\title{
The impact of training era on the outcomes of transurethral prostatectomy
}

Jeffrey D. Campbell'1; Jennifer Reid ${ }^{2}$; Michael Ordon ${ }^{3}$; Blayne Welk ${ }^{1,2}$

${ }^{1}$ Department of Surgery, Division of Urology, Western University, London, ON Canada; ${ }^{2}$ Institute for Clinical Evaluative Sciences (ICES), ON Canada; ${ }^{3}$ Department of Surgery, Division of Urology, University of Toronto, Toronto, ON Canada

Acknowledgements: This work was made possible by generous support from the MacMaster Fund for Urology through St. Joseph's Health Care Foundation. This study was supported by the ICES Western site. ICES is funded by an annual grant from the Ontario Ministry of Health and Long-Term Care (MOHLTC). Core funding for ICES Western is provided by the Academic Medical Organization of Southwestern Ontario (AMOSO), the Schulich School of Medicine and Dentistry (SSMD), Western University, and the Lawson Health Research Institute (LHRI). The opinions, results and conclusions are those of the authors and are independent from the funding sources. No endorsement by the St. Joseph's Health Care Foundation, ICES, AMOSO, SSMD, LHRI, or the MOHLTC is intended or should be inferred.

Cite as: Can Urol Assoc J 2020 March 30; Epub ahead of print. http://dx.doi.org/10.5489/cuaj.6204

Published online March 30, 2020

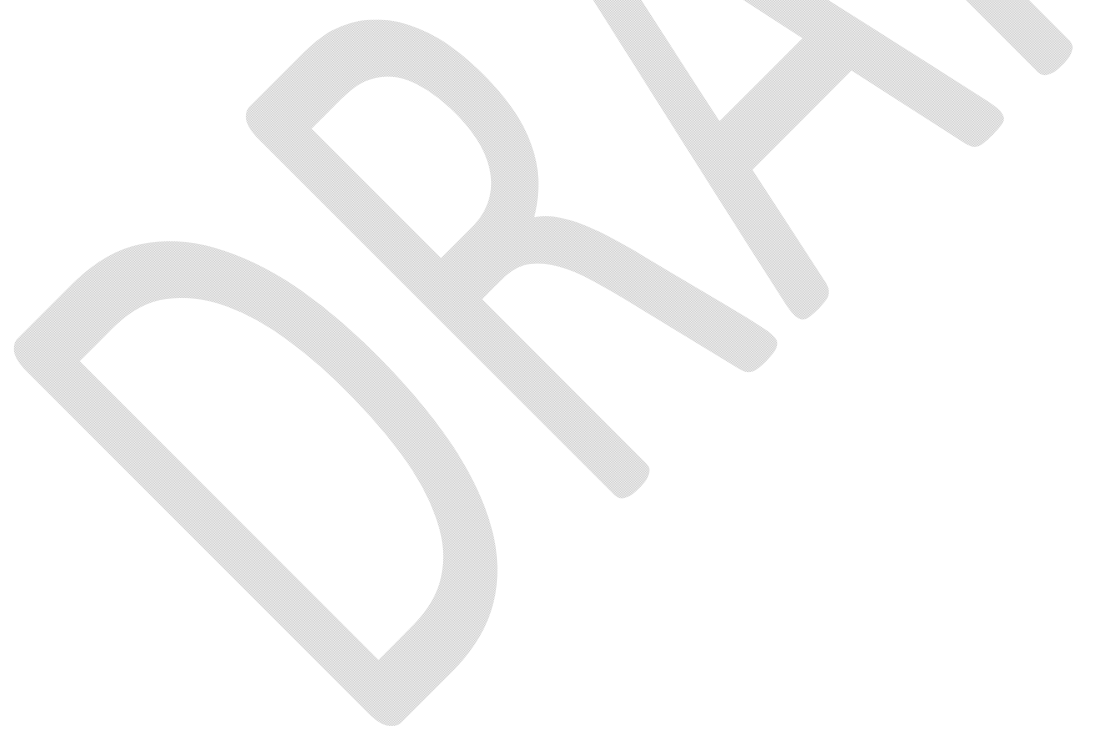




\section{Introduction}

Transurethral prostatectomy (TURP) is the gold-standard surgical treatment for benign prostatic hyperplasia (BPH). ${ }^{1,2}$ To optimize surgical proficiency and outcomes, a TURP requires a significant amount of practice. TURP was once the most common procedure in older patients (after cataract surgery), and therefore most urologists rapidly attained significant proficiency in this procedure. ${ }^{3}$ The rapid expansion of medical therapy in the 1990's and more recently of new surgical technologies has reduced the total number of electrosurgical TURP procedures being performed at most institutions. ${ }^{3}$ While trainees are adept at managing BPH-related lower urinary tract symptoms (LUTS) with medications, it has been our observation that some residents struggle with attaining surgical proficiency with TURP. Since TURP procedures typically occur after the failure of medical management, the patients tend to be more comorbid, of advanced age, and have larger prostates that have grown over years, thus making the cases more complex. ${ }^{1,2}$ It has been our impression that the volume of TURP procedures that residents are currently being exposed to is anecdotally lower than previously described by more senior surgeons who trained in the 1980's and 1990's. In addition, novel TURP procedures have been developed and are being taught at various institutions and this changing practice further dilutes resident experience of each individual technology.

Our objective was to determine if the reoperation rate after an initial TURP is different among urologist that were trained in a more contemporary era with predominately medical management of BPH symptoms compared to more senior urologists.

\section{Methods}

We conducted a retrospective, population-based, cohort study using routinely collected administrative datasets from the province of Ontario, Canada and held at Institute for Clinical Evaluative Sciences (ICES). We identified all men over the age of 40 years who had their first TURP between 2003-2016. We excluded patients with prior possible prostate cancer, TURP, or simultaneous bladder tumor resection. A full description of our data sources, methodology, covariates and coding definitions are included in our prior work. ${ }^{4}$ The primary exposure was the year of medical school graduation of the operating surgeon: those graduating prior to 1995 were considered part of the surgical management (higher-volume) era and those graduating after 1995 were considered part of the medical management (lower-volume) era of BPH. Our primary outcome was a repeat TURP being performed more than 14 days after the initial procedure. Secondary outcomes included 30-day emergency room visits, and 7-day blood transfusion rates. Several covariates were measured including year of procedure, type of hospital (academic versus community), TURP modality (electrical versus laser), indications for TURP, gross hematuria, urinary tract infections, acute urinary retention, diabetes, and concomitant bladder stone treatment. Baseline surgeon demographic information on the number of TURP procedures in the 5 years prior to the event date was measured. Our primary analysis was an adjusted marginal cox regression model with a robust sandwich covariance matrix which accounted for covariates, 
patient clustering within surgeons and the surgeon's prior TURP experience, ${ }^{5}$ our secondary analyses were adjusted logistic regression models. Adjustment was made for all patient covariates that had a statistically significant difference between groups. A p-value $<0.05$ was considered significant. All analyses were conducted using SAS version 9.4 (SAS Institute, Cary, NC). The use of data in this project was authorized under section 45 of Ontario's Personal Health Information Protection Act, which does not require review by a Research Ethics Board.

\section{Results}

We identified 78,176 men, with a median age of 72 years (IQR 65-79) that met our inclusion criteria. The majority of TURPs in our timeframe were performed by urologists in the highvolume era $(n=63,223)$ compared to those in the low-volume era $(n=14,953)$ (Table 1). A total of 314 different urologists performed TURPs over the study period, and median number of prior TURPs performed was 402 (IQR 232-720) for the high-volume generation versus 172 (IQR 73331) for the low-volume generation (Table 1).

After a median follow up of 5 years (IQR 2-8), the repeat TURP rate/100 person-years was $2.05(95 \%$ CI $2.00-2.10)$ for patients treated by the high-volume generation vs 2.63 (95\% CI 2.50-2.76) treated by the low-volume generation.

In our adjusted survival model (which also adjusted for number of prior TURPs), patients of the low-volume TURP generation had an increased hazard ratio for reoperation of 1.19 (95\% CI 1.11-1.26, $\mathrm{p}<0.01)$. In a subgroup analysis, the hazard ratio remained significant between the two groups for electrical TURPs (1.20; CI 1.01-1.42) but not for laser TURPs (HR: 1.08; CI: 0.91.29). The adjusted odds ratio for emergency room visits after TURP and perioperative blood transfusion were $1.01(95 \% \mathrm{CI} 0.97-1.06, \mathrm{p}=0.61)$ and $0.92(95 \% \mathrm{CI} 0.79-1.06, \mathrm{p}=0.22)^{6}$ between high and low volume surgeons.

\section{Discussion}

The monopolar TURP was the first successful, minimally invasive procedure in the modern era to treat BPH related LUTS, and impressively has remained the gold-standard surgical procedure over time. Our study demonstrates that patients of urologists that were trained after 1995, have a slightly higher repeat TURP rate compared to patients who had their procedure by more senior surgeons. This finding supports the hypothesis that current residents may not be achieving peak competency levels during their training compared to their predecessors. While there is certainly a learning curve for TURP, studies for other BPH technologies generally consider this to be only 50 cases, ${ }^{7}$ which most of the surgeons in this study have easily surpassed. The volume and feedback while performing TURPs during residency may be an important consideration for competency-based training. Due to the perceived lower number of TURPs in modern day urology, there may be an important role for simulator-based teaching, and community rotations during residency. Our results may be translatable to other urologic procedures which are becoming less common (including open surgical procedures). 
Limitations of our study include the fact that we do not have actual data on the number of TURPs performed during urology residency prior to 1995 versus after 1995. Not all relevant covariates could be measured (such as prostate size or weight resected). The difference in patient outcomes between these two groups of surgeons may be due to other factors, such as better patient selection, and this process may require a learning curve of hundreds of TURPs.

\section{Conclusions}

There is a difference in the outcomes of patients undergoing TURP based on whether their surgeon was trained prior to 1995 or after 1995, and this may be due to differences in surgical volumes during their training. 


\section{References}

1. Nickel JC, Aaron L, Barkin J, Elterman D, Nachabé M, Zorn KC. Canadian Urological Association guideline on male lower urinary tract symptoms/benign prostatic hyperplasia (MLUTS/BPH): 2018 update. Can Urol Assoc J. 2018;12:303-312.

2. Foster HE, Barry MJ, Dahm P, et al. Surgical Management of Lower Urinary Tract Symptoms Attributed to Benign Prostatic Hyperplasia: AUA Guideline. J Urol. 2018;200:612-619.

3. Wei JT, Calhoun E, Jacobsen SJ. Urologic diseases in America project: benign prostatic hyperplasia. J Urol. 2005;173:1256-1261.

4. Campbell J, Reid J, Ordon M, Welk B. The Utilization of Benign Prostatic Hyperplasia and Bladder-Related Medications After a Transurethral Prostatectomy. Urology. 2019;130:126-131.

5. Lipsitz SR, Parzen M. A jackknife estimator of variance for Cox regression for correlated survival data. Biometrics. 1996;52:291-298.

6. Welk B, Reid J, Ordon M, Razvi H, Campbell J. Population-based assessment of retreatment and healthcare utilisation after photoselective vaporisation of the prostate or electrosurgical transurethral resection of the prostate. BJU Int. 2019.

7. Brunckhorst O, Ahmed K, Nehikhare O, Marra G, Challacombe B, Popert R. Evaluation of the Learning Curve for Holmium Laser Enucleation of the Prostate Using Multiple Outcome Measures. Urology. 2015;86:824-829.

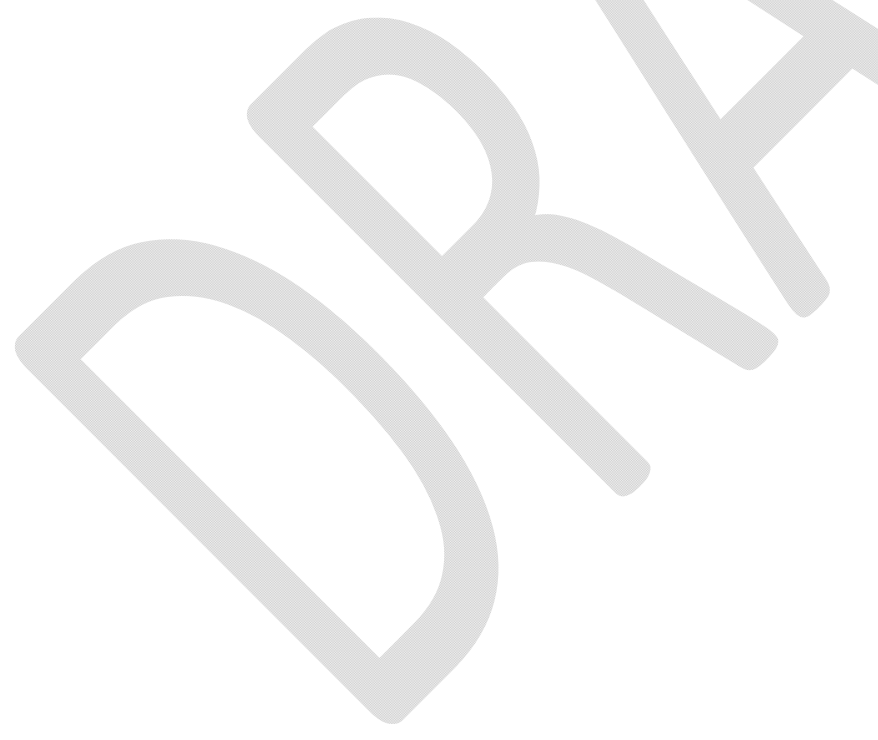


Figures and Tables

\begin{tabular}{|c|c|c|c|c|}
\hline Variable & Statistic & High-volume era & Low-volume era & $\mathbf{p}^{\mathbf{b}}$ \\
\hline Total patients & $\mathrm{N}$ & 63223 & 14953 & \\
\hline \multicolumn{5}{|l|}{ Demographics } \\
\hline Age & Median (IQR) & $72(65-79)$ & $71(64-78)$ & $<.01$ \\
\hline \multirow{2}{*}{$\begin{array}{l}\text { Type of hospital for } \\
\text { TURP }\end{array}$} & Academic & $7816(12.4 \%)$ & $1940(13.0 \%)$ & 0.05 \\
\hline & Community & $55407(87.6 \%)$ & $13013(87.0 \%)$ & \\
\hline $\begin{array}{l}\text { Gross hematuria } 6 \\
\text { months prior to } \\
\text { TURP }\end{array}$ & $\mathrm{N}$, yes $(\%)$ & $14253(22.5 \%)$ & $3388(22.7 \%)$ & 0.77 \\
\hline $\begin{array}{l}\text { UTI } 6 \text { months prior } \\
\text { to TURP }\end{array}$ & $\mathrm{N}$, yes $(\%)$ & $2218(3.5 \%)$ & $579(3.9 \%)$ & 0.03 \\
\hline $\begin{array}{l}\text { Acute urinary } \\
\text { retention } 6 \text { months } \\
\text { prior to TURP }\end{array}$ & $\mathrm{N}$, yes $(\%)$ & $26475(41.9 \%)$ & $6194(41.4 \%)$ & 0.31 \\
\hline \multirow{3}{*}{$\begin{array}{l}\text { Type of TURP } \\
\text { procedure }\end{array}$} & Laser & $6687(10.6 \%)$ & $2669(17.8 \%)$ & \multirow{3}{*}{$<.01$} \\
\hline & Electrical & $50316(79.6 \%)$ & $11119(74.4 \%)$ & \\
\hline & Unknown $^{\mathrm{a}}$ & $6220(9.8 \%)$ & $1165(7.8 \%)$ & \\
\hline $\begin{array}{l}\text { Concomitant bladder } \\
\text { stone treatment }\end{array}$ & $\mathrm{N}$, yes $(\%)$ & $5078(8.0 \%)$ & $1686(11.3 \%)$ & $<.01$ \\
\hline Diabetes & $\mathrm{N}$, yes $(\%)$ & $12516(19.8 \%)$ & $3306(22.1 \%)$ & $<.01$ \\
\hline \multicolumn{5}{|c|}{ Surgeon characteristics } \\
\hline $\begin{array}{l}\text { Years since medical } \\
\text { school graduation }\end{array}$ & Median (IQR) & $28(21-34)$ & $11(8-13)$ & \\
\hline $\begin{array}{l}\text { Prior number of } \\
\text { TURPs performed } \\
\text { by urologists }\end{array}$ & $\begin{array}{c}\text { Median (IQR) } \\
<250 \\
250-499 \\
500-749 \\
\geq 750\end{array}$ & $\begin{array}{l}402(232-720) \\
17594(27.8 \%) \\
20437(32.3 \%) \\
10247(16.2 \%) \\
14945(23.6 \%)\end{array}$ & $\begin{array}{c}172(73-331) \\
9765(65.3 \%) \\
3373(22.6 \%) \\
1185(7.9 \%) \\
630(4.2 \%)\end{array}$ & \\
\hline
\end{tabular}

a Some TURPs did not have an identifiable hospital procedure code that corresponded to either a laser or electrosurgical procedure. If both laser and electrical procedural codes were reported, we considered the type of TURP procedure unknown. ${ }^{\text {b }}$ Two-sided $p$-values were used to identify significant differences $(<0.05)$. IQR: interquartile range; TURP: transurethral prostatectomy; UTI: urinary tract infection. 